\title{
Saúde Reprodutiva, fecundidade e aborto provocado: análise de seis inquéritos populacionais realizados em São Paulo, Brasil
}

\author{
Reproductive Health, fertility and induced abortion: \\ the analysis of six population surveys carried out in \\ São Paulo, Brazil
}

Rebeca de Souza e Silva1, Carmen Linda Brasiliense Fusco ${ }^{2}$

Silva RS, Fusco CLB. Saúde reprodutica, fecundidade e aborto provocado: análise de seis inquéritos populacionais realizados em São Paulo, Brasil. Saúde, Ética \& Justiça. 2008;13(2):79-94.

Resumo: O Aborto Inseguro é, ainda, um grave problema de Saúde Pública e sua solução, um desafio a exigir medidas urgentes que passam, fatalmente, pelo processo de descriminalização do aborto. Conhecer o perfil das mulheres que recorrem ao aborto provocado, especialmente ao clandestino, inseguro, é de suma importância tanto para a área de Saúde Pública, em particular para a Saúde Reprodutiva, quanto para a área de Demografia. A partir da análise de 6 (seis) inquéritos populacionais, conduzidos em populações diferentes quanto à renda e quanto às características sociodemográficas, em São Paulo, nos últimos anos, as autoras procuram aproximar-se desse perfil.

Descritores: Medicina reprodutiva. Fertilidade. Aborto induzido. Epidemiologia.

O PAPEL do ABORTO NA TRANSIÇÃo dA FECUNDIDADE

U $\mathrm{m}$ balanço da literatura sobre a fecundidade revela que houve uma acentuada queda em seus níveis - em torno de $50 \%$ - neste breve período de 30 anos, na maioria dos países da América Latina. De um modo geral, passou-se de uma média de seis filhos por mulher a menos de três filhos por mulher nesse curto espaço de tempo ${ }^{1}$. Mais que isso, no Brasil, segundo a PNDS 2006, essas taxas continuaram declinando rapidamente, até atingir os níveis verificados hoje nos países Europeus, que se encontram abaixo do limite da necessidade de reposição populacional ${ }^{2}$.

Esse declínio encontra-se inversamente correlacionado com o nível socioeconômico da região. Dito de forma mais clara, as populações mais favorecidas economicamente - aquelas com níveis mais altos de renda e educação e com uma maior participação feminina na força de trabalho - foram as primeiras a atingir as mais baixas fecundidades.

No Estado de São Paulo, por exemplo, a taxa

\footnotetext{
${ }^{1}$ Profa. Associada do Departamento de Medicina Preventiva da Universidade Federal de São Paulo.

${ }^{2}$ Médica, advogada - Mestre em Epidemiologia do Departamento de Medicina Preventiva da Universidade Federal de São Paulo. Endereço para correspondência: Carmen L. B. Fusco. Rua Ceará, 101, apto. 111. São Paulo, SP. CEP 01243-010. E-mail: carmenlbf@uol.com.br
} 
de fecundidade nesse início de século alcançou o nível de reposição; em 2000 foi de 2.16 filhos por mulher e, em 2002, de 1,88 filhos por mulher, abaixo, portanto, do nível mínimo de reposição ${ }^{3}$. Apenas entre as mulheres menos escolarizadas, mais precisamente entre as que possuem um nível de instrução de até 3 anos, é que se observam taxas de fecundidade acima de 3 filhos por mulher.

Grosso modo, pode-se argumentar que o processo de transição da fecundidade foi iniciado pelos países desenvolvidos em meados da década de 50, mas foi alcançado mediante uma forte expansão social e melhoria dos níveis econômicos das populações mais pobres. Na América Latina em geral e no Brasil em especial, a partir da década de 70, essa transição ocorreu independentemente das melhorias sócio-econômicas e veio a reboque dessa tendência mundial. As melhorias sócioeconômicas foram muito mais tênues nesta região e, conseqüentemente, menos visíveis nesse proces$\mathrm{so}^{4}$. Em suma, a fecundidade começou a declinar entre os mais abastados e os mais pobres foram "incorporando" a prática de prole reduzida.

Seria isto louvável, se os baixos níveis de fecundidade reinantes na América Latina fossem fruto apenas de um maior acesso à contracepção e/ou ao uso mais adequado de métodos contraceptivos eficazes.

A verdade, contudo, é outra. Muito mais complexa e pouco alentadora. No Brasil, a grande maioria das mulheres não têm acesso sequer às informações necessárias para um controle efetivo da fecundidade, tampouco a serviços públicos de saúde que cuidem verdadeiramente do planejamento familiar preventivo ${ }^{4}$. Assim sendo, a despeito do ônus financeiro, algumas mulheres optam pela continuidade de uma gestação não planejada e/ou não desejada. E, no limite, mesmo a contra gosto, recorrem ao aborto provocado, não raras vezes realizado sob precárias condições de higiene e por profissionais não qualificados.

\section{Sobre os SERVIços de SAÚde REPROdUtiva}

Uma das principais causas subjacentes ao aborto provocado na América Latina é a falta de acesso a informações e/ou a serviços de "planejamento familiar"s.

Tal problema, seguramente, é mais grave entre adolescentes, uma vez que, a partir da década de
80 , a proporção de mulheres com menos de 20 anos que se tornou mãe aumentou consideravelmente em relação às décadas anteriores; essa proporção aumentou inclusive entre as menores de 15 anos de idade. Essa tendência permaneceu até finais da década de 90 , quando a proporção de mães adolescentes voltou aos patamares do início dos anos 80; não obstante, continua em patamares elevados. No Estado de São Paulo, por exemplo, em 2005, a proporção de mães adolescentes representava $16,6 \%{ }^{6}$.

Segundo Clotilde Charlot, especialista em desenvolvimento social da Unidade da Mulher no Desenvolvimento do BID, "a menos que se dê às mulheres de baixa renda a oportunidade de desenvolver qualificações que tenham mercado, de gerar renda, e reforçar sua auto-estima, os responsáveis pela prestação de serviços de planejamento familiar não conseguirão reduzir a gravidez não planejada"7.

Uma grande parcela das mulheres em situação de pobreza e, por conseguinte, mais necessitadas de assistência à saúde, certamente ainda terão de esperar anos para se beneficiar das parcas melhorias logradas neste terreno.

No México, por exemplo, um Programa de Serviços Sociais Essenciais combina metas anuais para expandir serviços de planejamento familiar aliadas à expansão de um programa de nutrição e aconselhamento para mulheres grávidas e lactantes.

Por outro lado, na Venezuela, a Associação Venezuelana para a Educação Sexual Alternativa (AVESA) dedica especial atenção à educação sexual de adolescentes, mediante o financiamento público de uma inovadora campanha de informação cujo alvo são adolescentes de famílias de baixa renda. A campanha inclui anúncios curtos pelo rádio e inserções em jornais com informações francas sobre formas de evitar a gravidez e doenças sexualmente transmissíveis. A AVESA ainda distribui material educativo a 60 escolas e organizações juvenis que já trabalham com jovens em situação de pobreza.

No Brasil, com o apoio da BENFAM, desde meados da década de 1990 funciona o programa PROESCOLA que possibilita o diálogo entre pais, alunos e professores, oferecendo aos alunos esclarecimentos sobre saúde sexual e reprodutiva, como se dá o acesso a preservativos, eqüidade de gênero etc ${ }^{8}$. Mas os programas estatais são 
bastante acanhados - farmácia popular com venda de anticoncepcional ("pílula") a preços baixos, distribuição de contraceptivos em centros de saúde, ainda numa visão retrógrada, na qual a mera distribuição de contraceptivos, ou o simples acesso a eles, seria o fator decisivo ao cumprimento dos direitos reprodutivos.

Se não se processar uma mudança fundamental na forma de prestação dos serviços de planejamento familiar, ou sua implantação completa, jamais será possível reduzir drasticamente a recorrência ao aborto provocado ilegalmente e, por conseguinte, todas as complicações físicas, psíquicas e sociais decorrentes de tal prática.

\section{ABorto e LEGISLAÇÃo BRASILEIRA}

O Código Penal brasileiro, em sua Parte Especial, Título I, "Dos Crimes Contra A Pessoa", em seu Capítulo I, "Dos Crimes Contra A Vida", penaliza o aborto, logo após os crimes de Homicídio, do art. 124 ao art. 128, sendo que neste último admite o aborto, praticado por médico, em dois únicos casos, a saber: I - quando é o único recurso para evitar a morte da gestante (aborto necessário); II - se a gravidez resultou de estupro e o aborto é precedido de consentimento da gestante ou, quando incapaz, de seu representante legal $\left.\right|^{9,10}$.

A despeito da clandestinidade do aborto no Brasil, constata-se que as leis são freqüentemente burladas. O país acaba por tolerar a existência de um grande número de clínicas particulares nas quais ocorre a prática clandestina do aborto de alto custo, em condições razoáveis ou boas de higiene, realizado por profissionais qualificados (médicos). Obviamente, as mulheres pobres não têm o privilégio do acesso a tais clínicas.

\section{Movimentos feministas e aborto na América Latina}

Segundo o movimento feminista, o corpo das muIheres é um território demarcado pelo patriarcado, que historicamente dele se apropriou, em decorrência de seu potencial produtivo e reprodutivo ${ }^{11}$.

Esse sistema patriarcal, tal como concebido pela visão feminista, e ainda reinante na maioria esmagadora dos países, leva a que, em pleno século $\mathrm{XXI}$, as mulheres padeçam de sérias restrições à sua autonomia, o que as impede de tomar decisões livres e responsáveis sobre seu próprio corpo. As mulheres não são, portanto, reconhecidas como sujeito de direitos, o que, certamente, acaba por afetar seu modo de vida e até sua saúde.

Assim sendo, os movimentos feministas não cessam de clamar pelo direito de as mulheres decidirem sobre sua vida, sua saúde e seu corpo, com autonomia e soberania plenas. Reivindicam, ainda, que a coerção e as violências de qualquer natureza sejam erradicadas, de sorte a garantir que as mulheres possam usufruir plenamente de seus direitos; tem sido proposta ainda a politização das demandas históricas em saúde e direitos sexuais e reprodutivos, de sorte que estes sejam reconhecidos como direitos humanos.

A expressão máxima dessas reivindicações, no campo da saúde, inegavelmente é a garantia de se prevenir a elevada mortalidade materna mediante a legalização do aborto provocado. Justamente porque a legislação restritiva sobre o aborto provocado, vigente na maioria dos países em desenvolvimento, em última instância acaba por conduzir a mulher a praticá-lo em condições precárias de higiene e saúde e, conseqüentemente, dessa prática surgem complicações que podem ser bastante graves e até mesmo fatais.

De fato, o compromisso primeiro das autoridades públicas deveria ser o de preservar a vida e a saúde das mulheres, elaborando programas, políticas públicas e/ou legislações que atendam a essas necessidades, sem qualquer interferência de credos ou religiões, uma vez que o Estado é laico. Contudo, o que se observa é que na maioria dos países em desenvolvimento, justamente os que mais padecem com a legislação restritiva, há o nítido predomínio da Igreja, sobretudo o da católica, sobre o Estado laico, da cultura sexista, das leis retrógradas, da postura machista, com a prevalência de mecanismos de controle do corpo feminino. Tudo isso, obviamente, serve de obstáculo ao reconhecimento dos direitos das mulheres e, conseqüentemente, dificulta as mudanças sociais com vistas à eqüidade de gênero, além de interferir na aprovação e implementação de políticas e legislações mais flexíveis, ou mais progressistas, no concernente aos direitos sexuais e reprodutivos.

A saúde sexual e reprodutiva das mulheres em geral, e das adolescentes em particular, deveria obter atenção preferencial das políticas públicas. $\mathrm{E}$ requereria, também, o reconhecimento social de que a sexualidade e a reprodução são terrenos 
Silva RS, Fusco CLB. Saúde reprodutiva, fecundidade e aborto provocado.

nos quais as pessoas devem estar capacitadas a tomar decisões responsáveis, informadas e livres, sem imposições de nenhum tipo. Isto foi destacado, de forma relevante, no Programa de Ação da Conferência Internacional sobre População e Desenvolvimento (CIPD) do Cairo, 1994, e em seus sucessivos seguimentos, nos quais se construiu o paradigma da saúde sexual e reprodutiva e se destacou o papel das mulheres como um eixo central para o desenvolvimento dos povos $^{12}$. A CIPD, não obstante, acabou subsumida por outras prioridades.

Alguns fatores adversos ao Consenso do Cairo: a agenda conservadora da administração Bush e a re-atualização da chamada Lei da Mordaça, 2001, que impede o uso de recursos da cooperação norte-americana por parte de ONGs de outros países, caso essas organizações ofereçam serviços de aconselhamento e pró-legalização do aborto ou, ainda, participem de debates políticos sobre essa temática ${ }^{13}$; as agressivas campanhas fundamentalistas da hierarquia católica em aliança com setores conservadores; os modelos econômicos neoliberais; as reformas estruturais dos Estados e a debilitação de seu papel social em áreas-chave como saúde e educação; o aprofundamento dos níveis de pobreza e conseqüente marginalização/ exclusão social; o aumento da violência em suas diversas facetas, dentre elas a violência contra as mulheres.

Conquistas preconizadas pelas Conferências INTERNACIONAIS

Na Conferência Internacional de População e Desenvolvimento, Cairo, em 1994, uma vez mais pelo empenho de movimentos feministas, foi dado um passo à frente para a garantia dos direitos das mulheres de decidir sobre "quando, onde, como e com quem ter filhos". A Conferência do Cairo, em seu Programa de Ação, reconheceu, também, pela primeira vez em um documento intergovernamental, o aborto inseguro como grave problema de Saúde Pública (parágrafo 8.25). Mais que isso, tratou de garantir o atendimento médico às mulheres com complicações decorrentes de um aborto provocado ${ }^{14}$.

O documento assinado na Conferência Mundial sobre a Mulher, em Pequim, em 1995, reafirmou o conteúdo do parágrafo 8.25 do Cairo, acrescentando a recomendação de que os países revisassem as leis que punem as mulheres, quando elas se submetem aos abortos ilegais (parágrafo 106k). Em 2000, o documento final, conhecido como Pequim +5 , incorpora na íntegra o texto do parágrafo 106k da Plataforma de Ação de Pequim, mencionando a necessidade de revisão das leis que punem a prática do aborto inseguro ${ }^{10,15}$.

O Plano de Ação da Conferência do Cairo além de legitimar, através de um documento de consenso internacional, o conceito de Direitos Reprodutivos, estabeleceu as bases para um novo modelo de intervenção na saúde reprodutiva, ancorado em princípios éticos e jurídicos comprometidos com o respeito aos Direitos Humanos ${ }^{10}$.

No entanto, no estabelecimento das metas do milênio, em setembro de 2000, verificou-se um retrocesso na área da saúde reprodutiva. A chamada Cúpula do Milênio, composta pelos países membros das Nações Unidas, ressaltou a necessidade de melhoria da saúde materna, recomendando uma queda de $75 \%$ da mortalidade materna até o ano de $2015^{16}$. As medidas de intervenção previstas para alcançar tal objetivo, entretanto, baseiam-se apenas na promoção e realização de partos "humanizados", assistidos por profissionais de saúde qualificados, e maior acesso aos métodos contraceptivos.

O ponto máximo do Objetivo 5 , meta 6 , das chamadas metas do milênio, portanto, é o de diminuir a mortalidade materna centralizando os cuidados de saúde no momento do parto, em detrimento do enfoque à mortalidade materna como referente à morte de mulheres por complicações ligadas à gestação, parto e puerpério, vigente desde $1987^{17}$ reenfatizado na CIPD, Cairo, em 1994, e que incluía o aborto como uma das formas de resolução possível, mesmo quando não desejável, da gestação (ressalte-se o peso relativo do aborto dentro das taxas de mortalidade materna $)^{14}$.

Paradoxalmente, entretanto, os objetivos do milênio não poderão ser atingidos sem que se tomem providências adequadas na área de população e saúde materna ${ }^{18}$. Assim é que segundo discurso proferido pelo atual Ministro da Saúde, José Gomes Temporão, em 28 de maio de 2007, na UNIFESP, "nos últimos 7 anos, apesar da adoção do parto humanizado, houve uma queda de apenas $6 \%$ na mortalidade materna brasileira"19

Ora, é público e notório que o aborto provocado é uma das primeiras causas de mortalidade materna, 
nos países que convivem com uma legislação a ele restritiva, e, certamente, a mais fácil de ser eliminada. No Brasil, o aborto é a principal causa de morte materna nos estados mais pobres e, nos outros, como São Paulo, é a quarta causa, apesar de sua clandestinidade - que leva à omissão deliberada desta ocorrência - e do amplo uso do Misoprostol - que dificulta a diferenciação entre aborto provocado e espontâneo ao diagnóstico.

Não é possível, portanto, reduzir expressivamente a mortalidade materna, sem atuar de forma direta na dinâmica do aborto provocado, em nosso meio. E não se pode ignorar, em hipótese alguma, que o aborto provocado só representa um sério risco de morbi-mortalidade materna quando realizado em precárias condições de higiene, por pessoal pouco qualificado, ou mesmo quando auto-provocado, sendo suas maiores vítimas as mulheres de baixa renda, uma vez que as mais abastadas pagam por serviços qualificados oferecidos por clínicas clandestinas, toleradas pela maioria dos países.

Mais que isso, a experiência dos países que convivem com uma legislação permissiva em relação ao aborto provocado nos ensina que os riscos associados a essa prática são mínimos, quando ela é realizada em condições de higiene e saúde adequadas.

De nada adianta culpar as mulheres que induzem o aborto; nenhuma delas provoca um aborto "por gosto", ao contrário, essa é uma decisão dificílima, sobretudo do ponto de vista psicológico e, certamente, só é adotada em casos extremos.

Obviamente, o ideal seria prevenir a ocorrência de uma gestação não planejada, não só facilitando o acesso aos métodos contraceptivos eficazes e inócuos, mas também, e fundamentalmente, oferecendo o acesso a um serviço de planejamento familiar eficiente e, de forma gratuita, um bom acompanhamento médico-ginecológico.

Entretanto, após mais de uma década das Conferências Internacionais do Cairo e Pequim (Beijing), no Brasil, e na maior parte da América Latina, o Aborto Inseguro é, ainda, um grave problema de Saúde Pública e sua solução um desafio a exigir medidas urgentes que passam, fatalmente, pelo processo de descriminalização do aborto $^{10}$. Já foi comprovado, reiteradamente, que o número de mortes causadas por aborto só é elevado nos países onde o aborto é ilegal, especialmente quando não praticado por pessoas qualificadas. $\mathrm{Na}$
América Latina, por exemplo, o aborto figura entre as principais causas de mortalidade materna sendo, não raras vezes, apontada como a principal ${ }^{20}$. A legislação restritiva, em total descompasso com a realidade, provoca uma "condição de clandestinidade" mediante a qual a grande maioria dos abortos se dá de forma insegura ${ }^{10}$.

\section{Aborto provocado e fecundidade no Brasil}

Tanto para o Brasil, quanto para o Estado de São Paulo, a aplicação de um modelo de decomposição da fecundidade, elaborado por Bongaarts ${ }^{21} \mathrm{em}$ 1980, permitiu destacar a importância dos métodos contraceptivos - na época, referindo-se quase que exclusivamente à pílula - e do aborto provocado, no acentuado declínio da fecundidade ocorrido no Estado de São Paulo - que, por sua vez, foi maior que o anotado no restante do país; apesar de o contraceptivo desempenhar papel decisivo nesse declínio, o aborto provocado aparece com importância acentuada. Aliás, acredita-se que este só não se apresenta com maior destaque devido à alta subestimação desse evento ${ }^{22}$.

Ou seja, em linhas gerais, pode-se argumentar que o declínio da fecundidade ocorrido no Brasil, na década de 70 , foi devido ao largo uso da pílula anticoncepcional e do aborto provocado. Na década de 80, uma grande parte desses métodos foi substituída pela esterilização feminina ${ }^{23}$. Atualmente, dados da PNDS 2006 revelam que $29 \%$ das usuárias de métodos contraceptivos encontramse esterilizadas ${ }^{2}$ Para melhor entendimento dessa grandeza, observe-se que na França a referida porcentagem é de $6 \%$, na Inglaterra de $7 \%$ e na Itália tão somente de $4 \%$.

O binômio aborto provocado e método contraceptivo talvez seja o expoente mais expressivo da pauta da saúde sexual e reprodutiva. Não obstante, por se tratar de assunto controverso, permeado por aspectos éticos, morais e legais, tornase difícil a obtenção de dados fidedignos sobre a efetiva necessidade das mulheres nessa esfera fundamental o que, por sua vez, inviabiliza a implementação de serviços públicos a ela adequados.

$\mathrm{Na}$ ausência de métodos contraceptivos ideais - o próprio preservativo tem alguma porcentagem de "falha" e, conseqüentemente, não é tido pelos especialistas como um método totalmente eficaz como contraceptivo - aumenta a probabilidade 
de ocorrer uma gestação não planejada e, por conseguinte, a da opção pelo aborto provocado. O déficit de contraceptivos adequados fica ainda mais evidenciado quando se leva em consideração a grande procura pela esterilização cirúrgica. Atualmente, para o direito à esterilização, no Brasil, a mulher deve ter pelo menos 25 anos de idade ou dois filhos nascidos vivos. Não raras vezes, entretanto, as mulheres têm seu segundo filho bem antes de completar 25 anos e, conseqüentemente, já podem se candidatar à esterilização cirúrgica - o que fazem, sem ao menos terem tido a possibilidade de conhecer os métodos contraceptivos reversíveis.

Segundo Vieira et al. ${ }^{24}$, a esterilização, sobretudo a feminina, continua em patamares acima do desejado entre as mulheres que iniciaram sua vida reprodutiva precocemente, isto é, antes de completar 18 anos de idade ${ }^{24}$.

Em suma, em nosso meio, para se evitar uma nova gravidez não planejada, ou mesmo indesejada, às mulheres unidas cabe a opção pela esterilização, mas, às solteiras, apenas um outro aborto ${ }^{25}$.

Resultado dos inquéritos popUlacionais SOBRE ABORTO PROVOCADO

Embora tenhamos realizado seis inquéritos domiciliares com o objetivo de caracterizar a epidemiologia do aborto provocado, até o momento apenas cinco deles foram analisados, posto que o referente à região da Saúde, ou mais precisamente à área de abrangência do P.S. Milton Santos, ainda não foi devidamente avaliado e não nos permite fazer qualquer comentário.

Por outro lado, embora todas as análises previstas para o cumprimento daquele objetivo sejam estritamente de cunho quantitativo, para a presente exposição não pretendemos entrar no mérito de como os resultados foram obtidos e tampouco nos propomos a exaltar suas propriedades estatísticas.

Nossa intenção é justamente a oposta, qual seja, de, à guisa de nossa experiência acumulada ao longo destes anos, aventar ao leitor as hipóteses a que a somatória dos resultados dessas pesquisas nos conduziu, explicitando, na medida do possível, as razões que nos fazem acreditar que o panorama do aborto provocado que trazemos à baila seja, a despeito de todo o problema de subestimação inerente a tal informação - pelos motivos já discutidos - aceitável, razoável, provável, ou condizente com a realidade.

Pois bem, em 1987, para a tese de doutoramento de Silva em 1992, foram entrevistadas 2.000 mulheres em idade fértil, residentes no antigo subdistrito de Vila Madalena ${ }^{25}$. As poucas questões abordadas no instrumento de coleta de dados - condição para a viabilização do emprego de uma técnica aleatória, conhecida pela sigla TRA, que visa a minimizar a subestimação de eventos estigmatizantes, como é o caso do aborto provocado 25,26 - foram reproduzidas em todos os demais inquéritos populacionais. Assim sendo, esse conjunto de questões, que doravante será denotado por "núcleo duro", permite, não de forma direta, a comparação de todos os inquéritos entre si desde o primeiro. Para que essa comparação seja possível, devem-se preservar as características sociodemográficas vigentes em cada contexto no momento da realização das entrevistas.

Assim, comecemos por anotar que no primeiro inquérito domiciliar foi possível detectar a situação privilegiada das moradoras de Vila Madalena. De fato, apresentaram uma média de apenas 2 filhos por mulher e uma renda mensal mediana de 7,5 salários mínimos. A título de comparação, nesse mesmo período, as estatísticas oficiais disponíveis revelavam para a Cidade de São Paulo uma média próxima a 3 filhos por mulher e uma renda mensal mediana inferior a 5 salários mínimos.

Apenas $13,6 \%$ das mulheres entrevistadas declararam espontaneamente ter provocado algum aborto no transcorrer de sua vida reprodutiva, dentre as mulheres sem filhos, bem como dentre as solteiras; contudo, essa porcentagem sobe extraordinariamente, atingindo a cifra de 68 abortos provocados para cada cem mulheres que chegaram a experimentar ao menos uma gestação ao longo da vida reprodutiva. Embora de forma menos marcante, entre as adolescentes de 15 a 20 anos de idade, essa mesma cifra gira em torno de $35 \%$.

Neste ponto, vale aclarar que o emprego da TRA detecta uma omissão de $80 \%$ dos abortos realizados no ano anterior ao da pesquisa, 1986. Mais precisamente, enquanto 8 mulheres em mil declararam espontaneamente a indução de um aborto, da TRA deriva uma estimativa de que 40 mulheres em mil lançaram mão dessa prática. Em que pese a possibilidade de sobrestimação desta técnica, o fato é que nos EUA, onde o 
aborto é legalizado, um inquérito domiciliar que se propôs a estimar a subinformação de aborto, entrevistando apenas mulheres que sabidamente tinham provocado algum aborto, deparou-se com um índice de não-resposta da ordem de $50 \%{ }^{27}$. Ou seja, não é de se estranhar em nosso meio, no qual vigora uma legislação restritiva sobre esta matéria, uma omissão de $80 \%$.

Observou-se, por outro lado, que as mulheres que mais omitem a prática do aborto são aquelas que mais recorrem a essa prática - solteiras, sem filhos, adolescentes, etc. Portanto, a análise do perfil de mulheres com aborto pode ficar prejudicada, mas não inviabilizada.

Isto posto, a partir de agora conduziremos as descrições analíticas sem mencionar a cada momento, inclusive para não aborrecer o leitor, o "drama" da alta subestimação. Não se deve, contudo, perdê-la de vista.

Em linhas gerais, o principal achado desta pesquisa (Vila Madalena) é o de que, uma vez grávidas - note-se que se faz um recorte das 2.000 mulheres entrevistadas e se analisa apenas aquelas com alguma gestação prévia, no intuito de refinar a análise, visto que só pode optar pelo aborto uma mulher que já engravidou - são as mulheres solteiras, sem filhos, entre 15 e 19 anos de idade, com escolaridade igual ou superior a 8 anos de estudo, que fazem uso de métodos contraceptivos não eficazes, as que recorrem mais amplamente à prática do aborto provocado.

Dentre as mulheres entrevistadas, observouse uma mediana de idade igual a 32 anos - digase de passagem que a distribuição etária dessas mulheres era similar à fornecida pelo IBGE para o sub-distrito de Vila Madalena - e, especificamente entre as solteiras, $42 \%$ do total de mulheres, essa mediana foi de 28 anos de idade. Quanto à nupcialidade, portanto, tanto quanto o que se verificou a respeito do comportamento reprodutivo e da renda familiar mensal, pôde-se constatar que as mulheres da região de Vila Madalena destoaram bastante do observado no Brasil como um todo, e na Cidade de São Paulo em particular, onde a idade média à primeira união girou em torno dos 22 anos de idade.

Essas mulheres são mais favorecidas em termos socioeconômicos, por conseguinte, como já visto, apresentam uma fecundidade mais reduzida do que aquelas de outras regiões da Cidade de São Paulo e do Brasil. Certamente essa fecundidade mais reduzida é alcançada tanto pela postergação do matrimônio, quanto pela larga recorrência ao aborto provocado por parte das mulheres solteiras e sem filhos. As mulheres casadas, via de regra com filhos, recorrem ao aborto provocado após terem atingido o número desejado de filhos - que segundo elas próprias, varia em torno de 2. Não obstante, essa situação é bem pouco freqüente nessa pesquisa e perde relevância frente ao comportamento das mulheres no início da vida reprodutiva.

Ademais, as mulheres casadas usam proporcionalmente mais métodos contraceptivos eficazes - pílula, DIU e/ou esterilização - do que as mulheres solteiras. Por se tratar de um estudo transversal, há como se saber se o aborto provocado ocorreu antes de as mulheres recorrerem aos métodos con-traceptivos, ou se ao contrário, por não utilizarem métodos contraceptivos eficazes, as mulheres solteiras, sem filhos, e adolescentes, acabaram se deparando com uma gravidez não planejada e, então, recorreram ao aborto provocado.

Seja como for, o fato é que, mesmo no momento da entrevista, pouquíssimas mulheres solteiras, em geral sem filhos, incluindo-se as que passaram pela desagradável experiência de abortar, faziam uso de métodos contraceptivos eficazes. A julgar pelo elevado nível sócio-econômico dessas mulheres, e pela experiência adquirida com a realização de outras pesquisas domiciliares, acreditamos que essas mulheres só não recorriam àqueles contraceptivos por absoluta falta de condições de implementálos à sua rotina de vida. Ora, a esterilização não estava, e continua a não estar, à disposição de mulheres nulíparas. Igualmente o DIU não era à época recomendado nessa circunstância e, além de não ser distribuído em Centros de Saúde, não era comprado com a facilidade de hoje. A pílula, por sua vez, apresentava muitos efeitos colaterais e, por fim, a instabilidade das relações afetivas deveria se constituir num desestímulo à opção por métodos contraceptivos eficazes, para essas muIheres em início da vida sexual e/ou reprodutiva. Enfim, mesmo numa situação bastante favorável do ponto de vista financeiro, não foi possível anular completamente a recorrência ao aborto provocado. Aliás, não é nada sensato julgar que essa seja uma tarefa exeqüível, como querem fazer crer os grupos anti-aborto. Nunca existiu e nunca existirá uma sociedade totalmente livre desta prática. Mais 
viável é aceitar esse fato e buscar minimizar os impactos negativos dela decorrentes, dos quais as mulheres mais pobres são as maiores vítimas. Aliás, aclare-se neste ponto, que a totalidade dos abortos, nessa pesquisa, foram provocados em clínicas particulares, com o mínimo de seqüelas físicas, uma vez que menos de $5 \%$ das mulheres que recorreram a esse procedimento relataram dores e/ou maior sangramento como complicações pós aborto.

$\mathrm{O}$ inquérito que se sucedeu a esse foi elaborado exatamente nos mesmos moldes metodológicos. Apenas por uma questão logística de alocação de verbas, dada a extensão geográfica da área a ser percorrida, o número de entrevistas sofreu uma pequena redução.

Assim sendo, foram entrevistadas 1.800 mulheres em idade fértil, residentes na cidade de São Paulo, em 1993. Seisanos após o primeiro inquérito, portanto; essas mulheres revelaram uma posição intermediária na escala socioeconômico-demográfica. Possuíam em média 2,4 filhos por mulher - valor maior que o obtido em Vila Madalena, apesar do processo de declínio da fecundidade observado no país, e em São Paulo particularmente, de forma ainda mais acentuada - e uma renda mediana de pouco menos de 5 salários mínimos.

Apenas $6,8 \%$ do total de mulheres admitiu um aborto provocado, e $12 \%$, dentre as mulheres sem filhos, mas com alguma gestação. Novamente o mecanismo da TRA foi utilizado para estimar a subinformação de abortos praticados no ano anterior ao da entrevista e, uma vez mais, encontramos a cifra de $80 \%$ de omissão.

Curioso, de fato, é o reduzido número de mulheres que se dispuseram a declarar a realização de um aborto. Difícil acreditar numa redução tão brusca na recorrência ao aborto provocado ao longo dos 6 anos transcorridos entre um inquérito e outro. Primeiro porque estamos falando de um período em que o "controle da fecundidade" se tornava cada vez mais ostensivo, inclusive através do roteiro de novelas do chamado "horário nobre" que não se cansavam de mostrar o quanto viviam bem as famílias com poucos filhos e, ao contrário, como padeciam as famílias numerosas. Segundo, porque, embora o acesso à esterilização e aos métodos contraceptivos estivesse se flexibilizando, tinham elas uma oferta muito inferior à demanda, como ocorre inclusive até os dias de hoje. Terceiro, porque, como veremos na seqüência, o perfil das mulheres que recorrem ao aborto provocado é quase idêntico ao detectado em Vila Madalena. Quarto e último, por que esse valor é muito próximo ao registrado pela pesquisa do Datafolha, onde a proporção de omissão supera os nossos $80 \%$.

Com respeito ao perfil nupcial, as mulheres deste segundo inquérito possuem comportamento distinto ao daquelas do primeiro inquérito. Há uma menor proporção de mulheres solteiras, pouco mais de $30 \%$, e, embora a idade mediana do conjunto das mulheres seja de 33 anos e, portanto, similar à referida anteriormente, a idade mediana das muIheres solteiras é de apenas 23 anos de idade. Constata-se, portanto, que o nível de fecundidade observado para a Cidade de São Paulo poderia ser, ao menos parcialmente, justificado pela nupcialidade precoce. Reforçaria essa justificativa o fato de haver uma proporção sensivelmente mais elevada do que a observada em Vila Madalena de mulheres que recorrem a contraceptivos eficazes, sobretudo entre as mulheres solteiras.

Não obstante, tudo leva a crer que essa reduzidíssima proporção de mulheres que declararam voluntariamente ter provocado algum aborto seja apenas o reflexo da maior participação de muIheres não-solteiras focalizadas pelo recorte da pesquisa. Nossa suspeita, portanto, é que uma parcela substantiva dos abortos desta região refira-se a abortos provocados antes do casamento - ou quando as mulheres ainda estavam solteiras - e ao serem elas entrevistadas, casadas, omitem o fato.

Supõe-se, então, que o fato de nosso inquérito ser focado em mulheres de 15 a 49 anos de idade é que, nesse contexto de nupcialidade precoce, nos remete à obtenção de uma proporção menor de "mulheres com aborto" do que a encontrada em Vila Madalena.

Contribuem bastante para a sustentação dessa hipótese os seguintes dados: há apenas 8 mulheres solteiras que referiram ter engravidado alguma vez, com idades entre 15 e 19 anos, mas 6 delas afirmaram ter optado pelo aborto provocado. Em síntese, nesta amostra, a proporção de abortos entre as mulheres jovens e solteiras foi altíssima, quase $80 \%$; todavia, por ser esta uma categoria que concentra um número reduzido de mulheres, desponta também um pequeno número total de episódios de interesse. Numa linguagem matemática, há menos casos de aborto no numerador dessa porcentagem apenas por conta 
da reduzida proporção de mulheres com "alto risco" de abortar dentre as 1800 entrevistadas.

Assim é que, à semelhança do comportamento delineado para Vila Madalena, frente a uma gestação consumada, são as mulheres solteiras, sem filhos, com idade entre 15 e 19 anos, e que fazem uso de métodos contraceptivos não eficazes, as mulheres que mais recorrem à prática do aborto provocado. A única diferença existente entre os dois contextos abordados até o momento é o fato de a escolaridade não se revelar um fator de substantiva importância para a ocorrência do evento de interesse.

O emprego da TRA permitiu estimar, em ambas as pesquisas, que a proporção de mulheres que provocam um aborto no período de um ano calendário foi cerca de $4 \%$. Passamos a sustentar a hipótese, bastante plausível frente ao cenário que se apresenta na América Latina, de que 40 a cada mil mulheres provocam aborto no transcorrer de um ano. Com isso, estimou-se na ocasião a ocorrência de 1,5 milhões de abortos/ano para o Brasil. Essa estimativa foi pautada na projeção do IBGE sobre a existência de cerca de 40 milhões de mulheres em idade fértil para o período 85/93. A referida estimativa encontra-se em ressonância com as estimativas divulgadas pelo IAG, no início da década de 90. Acreditamos na estabilidade da relação aborto/mulher /ano.

Em ambas as pesquisas já citadas, bem como nas demais a serem ainda referidas, o fato de a mulher ser favorável à prática do aborto provocado revela-se altamente associado à efetivação da prática. $\mathrm{O}$ que não se sabe é se elas recorrem ao aborto por serem mais flexíveis, se elas se revelam mais flexíveis por terem recorrido ao aborto ou, ainda, se as mulheres que declaram ser contrárias a esta prática, ou apenas aceitá-la nos casos previstos por lei, não omitem, em maior escala, a recorrência a um aborto. De qualquer forma, mesmo sem esta variável na análise, o grupo de fatores que explicam a recorrência ao aborto não se altera. Por isso, optamos por não mencioná-la neste trabalho. Gostaríamos tão somente de esclarecer, contudo, que a porcentagem de mulheres que não aceitam a indução de um aborto, ou aceitamna apenas nos casos previstos por lei, passou de cerca de $50 \%$ em 1987 a cifras próximas a $70 \%$ no biênio 2007/2008. Aliás, outro dado confirmado pela pesquisa Datafolha. Nítida guinada conservado- ra em pleno processo de conquistas feministas. Como explicá-la?

No ano de 2000, revisitamos o antigo sub-distrito de Vila Madalena, mas abdicamos do uso da TRA por absoluta restrição orçamentária. Assim, foram entrevistadas pouco menos de 900 mulheres em idade fértil selecionadas de forma aleatória - na verdade, entregamos 900 questionários que deveriam ser devolvidos após seu preenchimento e cerca de $5 \%$ deles foram entregues totalmente em branco. Foram 900 Questionários auto-preenchidos, entregues em envelope pardo, devolvidos lacrados pela entrevistada; 50 desses voltaram em branco, o que é tecnicamente aceitável.

Desta feita, encontramos uma média de 1,5 filhos por mulher e um valor de renda familiar mediana de 10 salários mínimos, ou seja, ainda mais alta que em 1987. Cerca de $20 \%$ do total de mulheres declarou ter provocado algum aborto, cifra ligeiramente maior que a obtida nessa mesma região, 13 anos antes. Não obstante, já esperávamos uma sensível melhora na qualidade da informação básica por conta da estratégia da coleta de dados.

Nesta ocasião, a idade mediana das 900 mulheres mostrou-se mais baixa que em 1987, a saber 28 anos de idade, mas, entre as mulheres solteiras, a idade mediana aproximou-se daquela do inquérito anterior, 26 anos; foi revelada também uma nupcialidade mais tardia do que na cidade de São Paulo, onde a idade média ao casamento era de 22 anos. A região rejuvenesceu, de fato, pois o grande número de estabelecimentos comerciais, sobretudo bares e restaurantes, afastou a população com mais idade e um grande número de universitários passou a morar nessa região. Assim é que observamos um incremento na proporção de mulheres solteiras, que chega ao patamar de $45 \%$, sendo que metade delas fez questão de frisar que possui namorado - embora elas não assumam esses namoros como relações afetivas estáveis. Esse fenômeno é bem peculiar ao século XXI, em que os jovens seguem morando na casa dos pais.

Quase $40 \%$ das mulheres solteiras declarou ter provocado algum aborto e uma proporção pouco menor - 36\% - o fez entre as mulheres em união consensual. Em nenhuma das outras pesquisas domiciliares, observou-se uma similaridade tão grande de comportamento nesses dois grupos de mulheres.

As adolescentes deixam de se destacar quanto 
à recorrência ao aborto provocado. Provavelmente mais instruídas e cuidadas de forma mais próxima pela família, devem estar sendo encaminhadas de forma mais precoce ao ginecologista, precavendose melhor de uma gravidez não planejada.

Há um número expressivo de mulheres com gestação mas sem filhos - 48 - no momento da entrevista. É a primeira vez que a proporção de mulheres desta categoria chega a chamar especialmente à atenção. Além disso, o dado mais alarmante a esse respeito é o de que a elas atrelam-se 69 gestações, todas tendo resultado em aborto provocado.

Por outro lado, neste contexto, além de a fecundidade ser baixíssima, mulheres jovens com um único filho não desejam uma nova gravidez.

O modelo matemático vai sendo simplificado ao longo dos anos; agora, apenas "não ter filhos" e "ser solteira" respondem pela maior recorrência ao aborto provocado diante de uma gestação indesejada; nem a escolaridade, nem a idade pesam na decisão pelo aborto. As mulheres e/ou casais buscam controlar a fecundidade a qualquer preço, e as gestações mais indesejadas socialmente são as primeiras a serem descartadas. Mesmo num momento de maior acesso a informações e a contraceptivos, numa população privilegiada economicamente, uma gestação inoportuna ocorre e com grandes chances de ser, literalmente, abortada.

Para o inquérito populacional conduzido no subdistrito de Vila Mariana, em 2007, junto a 1.120 mulheres em idade fértil, o modelo matemático fica ainda mais enxuto. Com efeito, apenas as mulheres sem filhos nascidos vivos delineiam o perfil de maior recorrência ao aborto provocado, frente a uma gravidez inoportuna e/ou não planejada.

Nesta pesquisa, metade das entrevistadas eram solteiras e a idade mediana do total de mulheres revelou-se como sendo a mais elevada, 37 anos. Em contrapartida e, coerentemente, revelou-se também a menor fecundidade - apenas 0,9 fiIhos por mulher. A região de Vila Mariana, tanto quanto a de Vila Madalena, é um reduto de classe média/alta; assim é possível visualizar com mais propriedade a sistemática queda de fecundidade. Mais que isso, levando-se em consideração que a proporção de usuárias de métodos contraceptivos eficazes não se alterou significativamente, fica evidenciado que essa queda se deu às custas de uma nupcialidade tardia e também do aborto provocado - que, voltamos a salientar, nunca deixará de existir.

A novidade, aqui, é que apenas $6,5 \%$ das muIheres relataram algum aborto provocado. No caso da cidade de São Paulo, com proporção similar a esta, foi diagnosticada uma baixa participação de mulheres solteiras. Não é o caso aqui. Há, portanto, duas hipóteses que podem ser aventadas na tentativa de explicar essa baixa proporção. A primeira, e que vem ao encontro do citado por vários pesquisadores, é que houve um decréscimo na proporção de mulheres que recorrem ao aborto provocado ${ }^{28}$. A segunda, é que por conta da retração na aceitação do aborto provocado (sobretudo pelo apelo religioso muito em voga nos dias atuais, com forças renovadas), o sub-relato de aborto provocado tenha-se intensificado.

Particularmente, compactuamos com essa segunda hipótese, por dois motivos em particular. Um dos motivos é o de que, pela primeira vez, terceirizamos o serviço de levantamento de dados por força do caráter multidisciplinar da pesquisa-mãe em que estava aninhada esta nossa pesquisa. Outro motivo, e o mais contundente, é a enorme quantidade de abortos declarados como Espontâneo, particularmente entre as mulheres casadas e sem filhos.

O inquérito da favela Inajar de Souza, realizado em 2005, com o Censo de mulheres entre 15 e 54 anos de idade, 375 no total, foi o primeiro a fazernos defrontar com um montante exageradamente elevado de abortos espontâneos. Nesse inquérito, foram declarados 82 abortos provocados e 62 abortos espontâneos ${ }^{10}$. Não há de ser mera coincidência, pois isso não existe em Ciência.

Essa população é extremamente jovem e, a despeito de possuir uma renda familiar mediana de apenas 2,5 salários mínimos, apresenta uma média de apenas 2,3 filhos por mulher, o que redunda em uma taxa proxy de fecundidade de 1,6. A fecundidade e o casamento mostram-se bastante precoces nessa população, sendo que a maior concentração de abortos se dá entre as mulheres que já completaram sua fecundidade, independentemente do fato de serem casadas ou solteiras; elas recorrem sobremodo ao aborto após atingirem o número de filhos considerado ideal.

Por último, entre as mulheres com alguma gestação, nessa comunidade, ser solteira e pouco escolarizada são os fatores que respondem pela maior recorrência ao aborto provocado. 
INQUÉRITO ATUAL SOBRE SAÚDE SEXUAL E REPRODUTIVA

A precocidade da união aliada a uma baixa fecundidade, observada nos Inquéritos sobre aborto provocado realizados na favela Inajar de Souza, causou-nos um certo desconforto. Primeiro, porque a manutenção desses baixos níveis de fecundidade se dá preponderantemente às custas de aborto provocado, com freqüentes complicações físicas. Já seria esperado que o ônus de um aborto clandestino recaísse sobre as mulheres mais pobres, como é o caso das moradoras dessa comunidade; entretanto, a precocidade com que isso ocorre nos deixou perplexas. Segundo, porque se bem é certo que elas recorrem ao aborto após terem atingido a fecundidade desejada, também é certo que o primeiro aborto provocado ocorre em média aos 21,9 anos de idade (50\% deles, até os 20 anos $)^{10}$.

Em suma, novamente, o peso do aborto clandestino recai sobre as mulheres logo no início de sua vida reprodutiva.

Não temos dúvida de que se a maioria dessas muIheres buscasse a esterilização no afã de prevenir uma nova gestação, elas não teriam acesso a essa prática, ou por serem muitos jovens, ou por terem menos que dois filhos nascidos vivos.

O discurso em voga na comunidade científica era, até há pouco tempo, o de que, por falta de recursos econômicos, as mulheres buscavam sair da casa dos pais através do casamento e uma gestação seria o atalho mais prático para essa nova vida.

Estudar com maior profundidade a dinâmica dessas relações entre aborto, fecundidade e contracepção, direcionou-nos à realização de um novo inquérito, mais abrangente que os anteriores em relação a essa dinâmica, sem abrir mão do núcleo duro de questões, com o objetivo de avaliar vários componentes da saúde sexual e reprodutiva, para ambos os sexos, na faixa etária de 15 a 24 anos, incorporando o "olhar" das relações de gênero.

Foram entrevistados 257 jovens - 123 do sexo masculino e 134 do sexo feminino. Dentre as 134 mulheres entrevistadas, 99 (cerca de 74\%) já haviam iniciado sua vida sexual e, por conseguinte, as 35 jovens sem vida sexual ativa não puderam dar informações relevantes ao tema em pauta. Assim sendo, embora para o cumprimento de nossos objetivos, todas as 134 mulheres estejam incluídas nos denominadores das proporções a serem estimadas, no aprofundamento do tema, apenas as $99 \mathrm{com}$ vida sexual ativa são consideradas. A média de idade do total de mulheres é de 18,8 anos; das que ainda não iniciaram sua vida sexual é de 15,6 anos e, das restantes, de 20,9 anos. Excluídas as 35 mulheres sem vida sexual ativa, resulta que somente 45 em 99 mulheres sexualmente ativas são solteiras. Levando-se em consideração que a média de idade dessas mulheres é de 16,6 anos, fica evidenciada a precocidade da nupcialidade nesta população feminina.

Igualmente, a fecundidade também é precoce - 56 mulheres, das 99 com vida sexual ativa, já tiveram ao menos uma gestação - mais precisamente, 37 delas tiveram uma única gestação e as outras 19 mais de uma.

A idade média das 134 mulheres é de 18,8 anos de idade sendo que entre as 56 mulheres com alguma gestação essa idade é estatisticamente mais elevada: 20,6. Dentre as mulheres com gestação, entretanto, não se verifica diferença de idade significativa entre as solteiras e casadas, nem entre as com aborto provocado e as sem aborto provocado.

A grande maioria das mulheres que tiveram alguma gravidez - quase $80 \%$ - afirmou que não desejava e/ou não planejara a(s) gestação(ões). E, mais da metade delas -29 ou cerca de $52 \%$ - usava algum método contraceptivo antes de engravidar, e 40 - mais de $70 \%$ - fazia uso de algum método contraceptivo no momento da entrevista. Ou seja, o defrontar-se com a possibilidade de uma outra gravidez não planejada incrementa a recorrência aos métodos contraceptivos.

A despeito da elevada proporção de mulheres que afirmaram não desejar a gravidez, apenas 6 delas - pouco mais de $10 \%$ - optaram por interromper deliberadamente a gestação.

Ou seja, em que pese a educação sexual oferecida pela ONG G\&A e a distribuição sistemática de contraceptivos, diante de uma gravidez inoportuna - o que sempre ocorrerá, mesmo nas sociedades mais desenvolvidas em termos socioeconômicos - as mulheres e/ou casais optam pela continuidade da gestação, via de regra por falta de condições de acesso ao aborto seguro. Por outro lado, $85 \%$ das mulheres com alguma gestação tiveram o apoio de seus companheiros na tomada de decisão sobre a interrupção ou continuidade da gestação (o oposto do ocorrido em pesquisa anterior, com mulheres de 15 a 54 anos, em que $86,4 \%$ das mulheres com Aborto provocado referiram não contar com o 
apoio dos companheiros quanto a essa decisão) ${ }^{10}$. Enquanto a grande maioria das mulheres sem gestação, $78 \%$, é solteira, apenas $30 \%$ daquelas com alguma gestação o são. Ou seja, há uma altíssima correlação entre nupcialidade e gestação precoce. Vale ressaltar que, neste inquérito, a maioria das gestações não desejadas foi atribuída a "falha" no uso (sic) da camisinha, ou uso inadequado de outros métodos contraceptivos.

Tal como ocorre com as entrevistadas do sexo feminino, a idade média entre os 123 homens participantes da pesquisa é de 18,3 anos. De forma similar, ainda, os 28 homens que reportaram ter engravidado alguma de suas companheiras são mais velhos: em média possuem 21,3 anos de idade.

Entretanto, dentre esses 28 homens, verifica-se uma diferença estatisticamente significativa entre as médias das idades de solteiros e de unidos ou casados - 20,2 para o primeiro grupo citado e 22,2 para o segundo - e, entre os que referiram ter a parceira provocado um aborto - 20,0 anos - e os que negaram essa prática - 21,9 anos. Entre esses homens, apenas os mais velhos são casados; os mais jovens, por sua vez, relataram proporcionalmente mais abortos provocados.

Mais detalhadamente, dos 102 homens que já iniciaram a vida sexual, 27 , isto é cerca de $35 \%$, afirmou ter engravidado alguma companheira. Embora a proporção de gestações seja estatisticamente menor que a observada no relato das mulheres, tanto quanto entre as mulheres, essas gestações são majoritariamente (85\%) consideradas indesejadas e/ou não planejadas. À diferença do que referem as mulheres, porém, menos da metade deles, 11, afirmaram ter filhos nascidos vivos e 9 - cerca de $32 \%$ - que suas companheiras interromperam, deliberadamente, alguma gestação.

O mais instigante é o fato de 8 dos 9 homens que relataram a experiência com $o$ aborto provocado referirem que a companheira, e/ou a mãe da companheira, foi "quem não queria o bebê". Alguns, inclusive, afirmaram que só tomaram conhecimento da gravidez após a realização do aborto. Apenas um alega ter tomado a decisão em conjunto com a companheira. Questionados sobre se assumiriam a paternidade caso as companheiras optassem pela continuidade da gestação, esses 8 homens responderam afirmativamente.

Entre esses homens que declararam ter engravidado alguma companheira (28), 9 deles, ou $32 \%$, usavam "camisinha" antes de a gravidez ocorrer e outros 10 referiram que a companheira usava "pílula" anticoncepcional (CO). Questionados sobre o que falhara, seis reportaram ter "estourado a camisinha", oito que não sabiam de fato o que houvera; um assumiu que poderia ter-se esquecido de usar a "camisinha" em alguma das relações sexuais e outro que, na pressa, deve ter colocado mal o preservativo. Os outros três afirmaram que a companheira "de-veria estar tomando pílula de farinha".

Quanto ao estado conjugal, a grande maioria dos homens é solteiro - 103 em 123 , ou $84 \%$. No entanto, entre os que nunca engravidaram uma companheira, essa proporção se eleva a 95\% e, ao contrário, cai para $50 \%$ entre aqueles que engravidaram alguma companheira. Ou seja, embora de forma menos acentuada, entre os homens, também se observa uma fecundidade precoce atrelada à nupcialidade precoce.

Por fim, nota-se que há um efeito "aparente" da desigualdade de gênero, quando se enfoca a proporção de mulheres com filhos nascidos vivos. Aparente porque é o fator idade quem melhor consegue explicar esse descompasso, como veremos a seguir.

Embora vivendo em condições de pobreza, os jovens moradores da Comunidade Favela Inajar de Souza têm alguma educação sexual por intermédio da ONG Gesto \& Ação ${ }^{10}$; têm acesso rotineiro a métodos contraceptivos, sobretudo ao preservativo masculino ("camisinha") e à "pílula" anticoncepcional; cuidam de sua saúde sexual e reprodutiva, tanto ao lançarem mão dos contraceptivos disponíveis, quanto ao fazerem os exames ginecológicos; os jovens de ambos os sexos relataram terem tido apoio de seus companheiros nas questões sexuais e reprodutivas; os homens jovens comportam-se de forma menos "machista" do que poderíamos supor a partir do inquérito anterior. Obviamente, esse comportamento não pode ser generalizado aos mais velhos. Não obstante, esses jovens deparamse, em grande escala, com uma gravidez indesejada e/ou não planejada, sobretudo por "falha" no uso do método contraceptivo (sic) - especialmente a "camisinha", visto que a maioria das mulheres que tentou fazer uso da pílula, segundo relato delas próprias, necessitou abandoná-la devido a efeitos colaterais. Reiteramos, com mais propriedade portanto, nossa idéia sobre a necessidade de se investirem recursos financeiros para a obtenção de 
um método contraceptivo eficaz e inócuo, e de fácil acesso, destinado ao início da vida sexual.

Diante de uma gravidez consumada, o relato das mulheres mostra que a opção por sua continuidade se dá com o devido apoio de seus companheiros. O relato dos homens, por outro lado, aponta que uma alta parcela deles optaria pela interrupção da gestação. Todavia, a grande maioria dos que referem a indução de um aborto alega que a companheira, ou a mãe dela, foi responsável por esta decisão, e que assumiria a paternidade no caso "delas desejarem o bebê".

Essa discrepância quanto à forma da resolução das gestações - aborto provocado ou nascimento vivo - deve-se, certamente, ao momento de vida dos parceiros. Como as mulheres tendem a se relacionar com homens mais velhos, torna-se mais fácil que estes optem pela continuidade da gestação mediante certo respaldo financeiro. Assim é que 20 das 57 mulheres com alguma gestação (35\%) já têm dois ou mais filhos e a grande maioria é casada.

Os homens, ao contrário, tendem a se relacionar com mulheres mais novas. Os homens casados, metade dos 28 que referiram alguma gestação de companheira, têm 22,5 anos, em média, versus 16,8 anos dos que não se depararam ainda com uma gestação. Por outro lado, aqueles que declararam algum aborto provocado da companheira são na maioria solteiros - $65 \%$ - e mais jovens - em média 20 anos de idade; mas mesmo esses, segundo eles próprios, se necessário, buscariam remediar a situação com o casamento ou, ao menos, assumiriam a paternidade.

Finalizando, saliente-se que, em pesquisa anterior, realizada entre mulheres em idade fértil residentes na Comunidade Favela Inajar de Souza, em 2005, observou-se uma média de somente 1,6 filhos por mulher (taxa proxy de fecundidade). A maioria dos nascimentos, $62,3 \%$, ocorreu antes de a mulher completar 25 anos de idade. A partir dessa idade, as mulheres continuaram a recorrer amplamente à prática do aborto provocado, no afã de controlar sua fecundidade ${ }^{10}$.

Não obstante, a população desta Comunidade revelou-se contrária à prática do aborto provocado. Também os jovens referiram sérias restrições à legalização dessa prática. Muito provavelmente, entre outros motivos, inclusive o religioso, porque a realidade dessa população aponta um altíssimo índice de complicações pós-aborto (cerca de 90\% entre as mulheres em idade fértil, em2005). Entre os jovens entrevistados, por exemplo, dos 11 homens cujas companheiras provocaram aborto, 6 delas apresentaram complicações. Também entre as 6 mulheres que relataram aborto provocado, 3 apresentaram complicações relacionadas a ele. Essa população deveria ser alertada para o fato de que legalizar o aborto provocado é imperativo para a preservação da saúde reprodutiva de populações pobres, sobretudo para as que não dispõem de educação sexual. Mesmo, na melhor das hipóteses, ou seja, na vigência de um novo contraceptivo inócuo e eficaz, haverá uma parcela de gestações não planejadas, principalmente entre os jovens; espera-se, em um futuro próximo, um declínio da idade ao primeiro aborto. Em um curto espaço de tempo, à semelhança das mulheres com maior renda, as mulheres mais pobres não medirão esforços para entrar no mercado de trabalho às custas de mais anos de estudo. É até provável também que, no limite, a morbidade relacionada ao aborto provocado seja reduzida. Pouco provável, entretanto, é que elas não trilhem um caminho similar ao das mais favorecidas economicamente, buscando postergar o nascimento do primeiro filho e, por conseguinte, recorrendo ao aborto, sobretudo na primeira gestação.

\section{Considerações finais}

Nos contextos sócio-economicamente mais favorecidos, Vila Madalena e Vila Mariana, houve uma acentuada redução no número médio de filhos por mulher em idade fértil. Passou este de 2,2 em 1987 a 0,9 em 2007. Ou seja, um declínio da ordem de $60 \%$ em um período de 20 anos. A proporção de usuárias de métodos contraceptivos, todavia, não se alterou de forma tão marcante nesse mesmo período de tempo - passou de 46 para 58 a cada 100 mulheres em idade fértil e, portanto, experimentou um incremento da ordem de $25 \%$.

Um maior acesso aos métodos contraceptivos não se revela, portanto, nesses estudos, um fator preponderante à queda da fecundidade. A idade à primeira gestação, por outra parte, aumentou consideravelmente nos últimos 30 anos, passando de 22 a 28 anos de idade nestes contextos.

A ocorrência de gestações indesejadas e/ou não planejadas esteve presente por todo esse período. No início, dentre as mulheres solteiras, 
Silva RS, Fusco CLB. Saúde reprodutiva, fecundidade e aborto provocado.

jovens, sem filhos e mais escolarizadas. No final, ficaram circunscritas às mulheres sem filhos. A nova dinâmica das relações de gênero, na qual o casamento não se revela mais como forma de realização da mulher, aliada às novas oportunidades de estudo e trabalho justificam esse panorama.

Obviamente, o aborto provocado torna-se a única opção que a mulher tem para não se deparar com um nascimento inoportuno. Nesse sentido, não é possível acreditar que a proporção de abortos tenha caído de $12 \%$ para $6,8 \%$ (cidade de São Paulo, 93). Mais sensato é supor que houve um aumento no nível de omissão do aborto provocado. Primeiro, porque em 2000 , através de questionário indireto - sigiloso - essa proporção atingiu a cifra de $20 \%$. Segundo porque houve uma nítida guinada conservadora de opinião nos últimos anos, de sorte que de $62 \%$ de mulheres favoráveis à prática do aborto - pelos motivos previstos por lei e/ou por motivos econômicos - chegou-se a 48\% em 2007.

Na população da favela Inajar de Souza, o número médio de filhos por mulher - 1,6 - apesar de baixo, supera o obtido em Vila Mariana. A proporção de usuárias de métodos contraceptivos, contudo, é bastante similar - menos de $60 \%$. A idade média ao primeiro nascimento é reduzidíssima para os dias atuais $-17,5$ anos de idade. ${ }^{10}$ A proporção de gestações indesejadas é altíssima - cerca de $80 \%$ entre os jovens de 15 a 24 anos de idade. $\mathrm{E}$, como não poderia deixar de ser, o aborto assume papel de destaque na manutenção de níveis baixos de fecundidade. A falta de perspectiva profissional dessas mulheres leva-as à maternidade precoce e à impossibilidade de sustentar os filhos - sobretudo no caso de a mulher não ter um parceiro - portanto as conduz à prática do aborto provocado. Uma altíssima proporção de mulheres - 18\%, em 2007, e $22 \%$, em 2005 - declarou espontaneamente que recorreu a essa prática. Mesmo considerando-se a relação de confiança existente entre a ONG que efetuou a pesquisa de campo e as moradoras da Comunidade Inajar, certamente há, como nos outros contextos, uma acentuada omissão desse evento.

As mulheres pobres não podem ser mães - por imposição da sociedade - e tampouco podem-se beneficiar das conquistas feministas.

Silva RS, Fusco CLB. Reproductive health, fertility and induced abortion: the analysis of six population surveys carried out in São Paulo, Brazil. Saúde, Ética \& Justiça. 2008;13(2):79-94.

Aвstract: Unsafe abortion is still a major public health issue and its solution is a challenge, implicating in the enforcement of urgent measures which necessarily include the decriminalization of abortion. The knowledge of the profile of women who recourse to induced abortion, especially the ones who are submitted to clandestine, unsafe abortions, is essential for the areas of Public Health and Demography. The authors intend, in this study, to outline this profile by analyzing 6 (six) population surveys, conducted in samples of women living in São Paulo, who had distinct income and sociodemographic characteristics.

Descritores: Reproductive medicine. Fertility. Abortation, induced. Epidemiology.

\section{REFERÊNCAIS}

1. Alan Guttmacher Institute. Aborto clandestino: una realidad latinoamericana. Nueva York: Alan Guttmacher Institute; 1994 [Acesso em: 13 jul. 2006] Disponível em: http://www.womenslinkworldwide.org/ pdf/sp_proj_laicia_amicus_app_agisp.pdf.

2. Brasil. Ministério da Saúde. PNDS 2006: Pesquisa Nacional de Demografia e Saúde da Criança e da Mulher. Relatório. Brasília: Ministério da Saúde; 2008 [Acesso em: 20 jul. 2008]. Disponível em: http://bvsms. saude.gov.br/bvs/pnds/img/relatorio_final_pnds2006. pdf.
3. Yazaki LM. Fecundidade da mulher paulista abaixo do nível de reposição. Estudos Avançados (São Paulo). 2003;17(49):65-8.

4. Carvalho JAM, Brito F. A demografia brasileira e o declínio da fecundidade no Brasil: contribuições, equívocos e silêncios. Rev Bras Estudos Populacionais (São Paulo). 2005;22(2):351-69.

5. Fundo de População das Nações Unidas. A situação da população mundial, 2002. Nova lorque: UNFPA; 2002.

6. Secretaria de Estado da Saúde de São Paulo. São Paulo reduz gravidez na adolescência em 32\% [Acesso em 20 jul. 2008] São Paulo: Secretaria da 
Saúde; 2007. Disponível em: http://portal.saude. sp.gov.br/content/rumeuijele.mmp. .

7. Constance P. O outro lado da revolução reprodutiva: algo mais além da queda na taxa de natalidade. BID América (New York). 1997;7(2) [Acesso em 20 jul. 2008]. Disponível em: http://idbgroup.org/idbamerica/ archive/stories/1997/por/7d2.htm.

8. Ferraz E, Quental I, Schwenck C, Costa N. Saúde sexual e reprodutiva para adolescentes: a experiência do projeto Proescola. In: Encontro Nacional de Estudos Populacionais, ABEP, 14., 2004, Caxambu, MG. Anais. Campinas (SP): Associação Brasileira de Estudos Populacionais; 2004 [Acesso em 20 jul. 2008]. Disponível em: http://www.abep.nepo.unicamp. br/site_eventos_abep/PDF/ABEP2004_232.pdf.

9. Brasil. Decreto-lei no 2.848 , de 07 de dezembro de 1940. Código Penal. Diário Oficial [da] República Federativa do Brasil, Poder Executivo, Brasília, DF, 31 dez. 1940 [Acesso em 20 jul. 2008]. Disponível em: http://www010.dataprev.gov.br/sislex/ paginas/16/1940/2848.htm\#PE_T1_CP1.

10. Fusco CLB. Aborto inseguro: freqüência e características sócio-demográficas associadas, em uma população vulnerável - Favela Inajar de Souza, São Paulo [Dissertação]. São Paulo: Universidade Federal de São Paulo; 2006.

11. Foucault M. História da sexualidade: a vontade de saber. 17a ed. Rio de Janeiro: Graal; 2006.

12. Naciones Unidas. Programa de Acción de la Conferencia Internacional sobre la Población y el Desarrollo. Derechos reproductivos y salud reproductiva. Párrafos 7.2-7.11. In: Informe de la Conferencia Internacional sobre la Población y el Desarrollo: el Cairo, 5 a 13 de septiembre de 1994. Nueva York: Naciones Unidas, 1995a. cap. vii, p. 37. [A/CONF-171/13/Rev.1] [Acesso em 20 jul. 2008]. Disponível em: http://www.unfpa.org/upload/lib_pub_ file/572_filename_finalreport_icpd_spa.pdf.

13. Corrêa S. Cairo + 10: a controvérsia que não acabou. In: Caetano AJ, Alves JED, Corrêa S. Organizadores. Dez anos do Cairo: tendências da fecundidade e direitos reprodutivos no Brasil. São Paulo: Associação Brasileira de Estudos Populacionais, Fundo de População das Nações Unidas; 2004 [Acesso em 20 jul. 2008]. Disponível em: http://www. abep.nepo.unicamp.br/docs/outraspub/cario10/ cairo10correa49a58.pdf.

14. Naciones Unidas. Programa de Acción de la
Conferencia Internacional sobre la Población y el Desarrollo. Salud de la mujer y la maternidad sin riesgo. Párrafo 8.25. In: Informe de la Conferencia Internacional sobre la Población y el Desarrollo: el Cairo, 5 a 13 de septiembre de 1994. Nueva York: Naciones Unidas; 1995b. cap. viii, p. 56. [A/CONF171/13/Rev.1] [Acesso em 20 jul. 2008]. Disponível em: http://www.unfpa.org/upload/lib_pub_file/572_ filename_finalreport_icpd_spa.pdf.

15. Naciones Unidas. Plataforma de Acción. La mujer y la salud. Párrafo 106k. In: Informe de la Cuarta Conferencia Mundial sobre la Mujer: Beijing, 4 a 15 de septiembre de 1995. Nueva York: Naciones Unidas, 1996. cap. iv, p. 42. [A/CONF.177/20/Rev.1] [Acesso em 20 jul. 2008]. Disponível em: http:// daccessdds.un.org/doc/UNDOC/GEN/N96/273/04/ PDF/N9627304.pdf?OpenElement.

16. United Nations. Resolution n. 55/2, of 8 September 2000. United Nations Millennium Declaration. In: General Assembly. New York: United Nations; 2000 [Acesso em 9 ago. 2008]. Disponível em: http://www. un-ngls.org/pdf/A-RES-55-2.pdf.

17. International Safe Motherhood Conference, 1987, Nairobi, Kenya. Washington (DC): World Bank; 1987.

18. Laurenti R, Jorge MHPM, Gotlieb SLD. A saúde materna e os objetivos de desenvolvimento do milênio. Rev Saúde (São Paulo). 2007;1(1) [Acesso em 20 jul. 2008]. Disponível em http://www.revistas. ung.br/index.php/saude/article/viewFile/63/98.

19. Temporão JG. Políticas públicas de direitos sexuais e reprodutivos. In: Seminário Saúde, Direitos Sexuais e Reprodutivos: Subsídios para as Políticas Públicas, 2007, Rio de Janeiro. Rio de Janeiro: Universidade Federal do Rio de Janeiro; 2007.

20. Organización Panamericana de la Salud. Unidad de Género y Salud. Equidad de género y salud en las Américas a comienzos del siglo XXI. Washington: OPS; 2004.

21. Bongaarts $\mathrm{J}$. The fertility inhibiting effects of the intermediate fertility variables. In: Seminar on the Analysis of Maternity Histories, 1980, London. Papers. Paris: International Union for the Scientific Study of Population and World Fertility Survey; 1980.

22. Berquó ES, Faria VE. Migrações e fecundidade em quatro contextos brasileiros. In: Conselho Latinoamericano de Ciências Sociais. Reproducción de la población y desarrollo. Montevidéu: Clacso; 1985. 
Silva RS, Fusco CLB. Saúde reprodutiva, fecundidade e aborto provocado.

23. Fundação Sistema Estadual de Análise de Dados. A fecundidade da mulher paulista. São Paulo: Fundação Sistema Estadual de Análise de Dados; 1994. (Informe Demográfico, n. 25).

24. Vieira EM, Fábio SV, Gueleri W, Picado MP, Yoshinaga $E$, Souza L. Características dos candidatos à esterilização cirúrgica e os fatores associados ao tipo de procedimento. Cad. Saúde Pública, (Rio de Janeiro) 2005;21(6):1785-91.

25. Silva RS. Aborto provocado: sua incidência e características: um estudo com mulheres em idade fértil (15 a 49 anos), residentes no subdistrito de Vila Madalena [Tese]. São Paulo: Faculdade de Saúde Publica, Universidade de São Paulo; 1992.

Artigo recebido em 22/05/2008. Aprovado em 07/08/2008.
26. Silva RS. Especulações sobre o papel do aborto provocado no comportamento reprodutivo das jovens brasileiras. Rev Bras Estudos População (São Paulo). 19(2):249-61.

27. Singh S, Wulf D. Estimated levels of induced abortion in six Latin American countries. Int Fam Planning Perspec (New York). 1994;20(2):20(1):4-13

28. Monteiro MFG, Adesse L, coordenadores. Seminário Magnitude do Aborto do Brasil: uma Análise dos Resultados de Pesquisa, 2007. Rio de Janeiro. Rio de Janeiro: Universidade Estadual do Rio de Janeiro, 2007 [Acesso em 20 jul. 2008]. Disponível em http:// www.ims.uerj.br/downloads/ipas_ims_seminario_ aborto.pdf. 